\title{
A National Palliative Care Strategy for Canada
}

\author{
R. Sean Morrison, MD
}

\begin{abstract}
Objective: To identify barrier to achieving universal access to high quality palliative care in Canada, review published national strategies and frameworks to promote palliative care, examine key aspects that have been linked to successful outcomes, and make recommendations for Canada.

Background: In 2014, the World Health Organization called on members to develop and implement policies to ensure palliative care is integrated into national health services.

Methods: Rapid review supplemented by the author's personal files, outreach to colleagues within the international palliative care community, review of European Association for Palliative Care publications, and a subsequent search of the table of contents of the major palliative care journals.

Results: Frameworks were found for 10 countries ranging from detailed and comprehensive multi-year strategies to more general approaches including laws guaranteeing access to palliative care services for "dying" patients or recommendations for the development of clinical infrastructure. Few formal evaluations were found minimal comparative data exist regarding the quality of care, access to palliative care services, timing of access in the disease trajectory, and patient and family satisfaction with care. Factors that appear to be associated with success include: 1) input and early involvement of senior policy makers; 2) comprehensive strategies that address major barriers to universal access and that involve the key constituents; 3) a focus on enhancing the evidence base and developing a national system of quality reporting; and 4) substantial and sustained government investment.

Discussion: Comprehensive national strategies appear to improve access to high quality palliative care for persons with serious illness and their families. Such strategies require sustained government funding and address barriers related to infrastructure, professional and public education, workforce shortages, and an inadequate evidence base.
\end{abstract}

Keywords: Canadian framework; health policy; palliative care

\section{Introduction}

I N 2014, the World Health Organization (WHO) called on members to develop and implement policies to ensure evidenced-based, effective, and equitable palliative care is integrated into national health services as an element of the continuum of care. ${ }^{1}$ Yet in 2016, palliative care remains inaccessible to many Canadians (see Roulston from this same issue). Most healthcare professionals lack knowledge and skills in the core palliative care domains-pain and symptom assessment and management, communication, care coordination, and most Canadians are only vaguely aware of the benefits of palliative care and how and when to access it. ${ }^{2}$

In Canada, as has been the case in most high income countries, palliative care's development has been organic rather than strategic. It has been largely influenced by local resources and practices, intermittent infusions of government and philanthropic funding, and recommendations and guidelines from specialty societies.
To date, some progress has been made toward the development of a comprehensive national government strategy. The Way Forward ${ }^{3}$ has been promoted by the Canadian and Hospice Palliative Care Association. Palliative Care Matters itself is an example of convergent evaluation built upon 19 prior national efforts (see Fassbender from this same issue). Highly anticipated legislation, Bill C-277, ${ }^{4}$ would compel Health Canada to develop and implement a national framework within five years. Accountability for health, however, falls under provincial jurisdiction and is reflected in a myriad of provincial frameworks such as the one for Alberta. ${ }^{5}$

Public support for the development of a national strategy is strong. A recent survey (see Roulston from this same issue) revealed that a solid majority $(86 \%)$ of Canadians expect the federal government to develop and implement national standards for palliative care; that public support for integrating national standards for palliative healthcare services into the Canada Health Act is quite widespread (85\% $)$; and almost 9-in-10 (89\%) Canadians agree that a document outlining 
the federal government's plan for implementing a palliative care program should be readily available for all Canadians. Many (70\%) were concerned about the additional costs of implementing a national palliative care strategy (NPCS).

This article reviews barriers that need to be overcome to achieve universal access to high quality palliative care. It also reviews published national strategies and frameworks to promote palliative care, examines key aspects that have been linked to successful outcomes, and makes recommendations for Canada. These include references to integrated palliative care providing services throughout the illness trajectory and across all care settings and the palliative approach embedding palliative competencies across all care providers. Integrated care is described in another article in this issue (see Brazil this same issue). Harmonizing the terminology and definitions of access and palliative care are outside the scope of this article.

\section{Barriers to accessing high quality palliative care}

Barriers to access to quality palliative care are relatively universal across high income nations and can be categorized into four key areas:

- Lack of public and professional awareness of the benefits of palliative care;

- Workforce shortages;

- A lack of infrastructure and care delivery models and;

- An inadequate evidence base.

A major issue impeding access to palliative care is the perception among doctors and other healthcare professionals that palliative care is appropriate only at the end of life, is synonymous with hospice or end-of-life care, and that patients will react negatively and lose all hope if palliative care referral is discussed. ${ }^{6,7}$ Perhaps this is not surprising: Most Canadian clinicians receive little to no training in the core knowledge and skills of palliative care, nor exposure to modern palliative care teams during educational training. ${ }^{2}$

While many physicians have misperceptions about palliative care, many patients simply do not know about it. A recent survey of a representative sample of Canadians (see Roulston from this same issue) reported that only $58 \%$ of adults in Canada were aware of palliative care and only $16 \%$ reported being very aware. Most learned of palliative care from word of mouth and over $85 \%$ agreed that a public awareness campaign should be undertaken.

Workforce shortages also prevent many patients from accessing or using palliative care services. The number of palliative care specialists falls far short of what is necessary to serve the current population. ${ }^{8}$ The Royal College of Physicians and Surgeons of Canada only recently approved a two-year subspecialty training program in palliative medicine to replace the 12-month residency program that was conjointly accredited by the College of Family Physicians of Canada. ${ }^{2}$ Similar shortages exist across the other core palliative care disciplines of nursing, social work, and chaplaincy. ${ }^{8}$ Work done by colleagues in the United Kingdom and Australia suggest that specialist programs would need to be tripled in size to accommodate the entire population. ${ }^{9-11}$

Creating a specialist workforce is not enough, however, to ensure that patients with serious illness and their families receive the care that they deserve. The specialist workforce will never be large enough to meet the needs of those Ca- nadians with serious illness and their families. ${ }^{8}$ Enhancing the palliative care knowledge and skills of ALL front-line clinicians must occur if care for the seriously ill is to improve.

Unfortunately, the core palliative care competencies of skilled communication, expert pain and symptom management, and psychosocial assessment remain, at best, a small part of most medical school and residency training programs in Canada. $^{2}$ As a result, the vast majority of practicing physicians and trainees have either rudimentary or no skills in these areas, which negatively affects patient and family outcomes. Expanding core palliative care knowledge and skills of all clinicians will be a key step toward resolving the shortage in the palliative care specialist workforce.

The existing palliative care infrastructure needs to be enhanced and new models of care delivery-particularly for patients living at home, in nursing homes, and in rural areas of the country where access to palliative care specialists and competencies are extremely limited. Existing palliative care programs are often stretched to capacity due to staffing constraints and thus often triage services to the most complex patients or those closest to the end-of-life thus limiting access to many patients and families that could otherwise benefit from palliative care. ${ }^{2}$

Federal Investment in needed palliative care research is dwarfed by other areas of medicine. Although CIHR launched a highly publicized six year palliative care research initiative 2003, annual funds devoted to it represented only $0.3 \%$ of the annual CIHR budget (www.cihr-irsc.gc.ca/e/27756.html).

In 2015-2016, CIHR awarded 19 grants in palliative care totaling $\$ 2,725,822$ dollars $(0.03 \%$ of the annual research budget). It is notable that palliative care, hospice, pain, symptoms, decision making, advance care planning, end-oflife are all absent from CIHR's key word search engine (http://webapps.cihr-irsc.gc.ca/funding/search_e).

As a result, unlike other areas of medical research traditionally funded by CIHR, the knowledge and evidence base to support core elements of palliative care clinical practice (i.e., pain and symptom management, communication skills, care coordination) is inadequate.

The reasons for this distressing state of affairs are many, but almost all stem from a philosophy of medical research that has traditionally viewed symptoms and suffering as unimportant in themselves and interesting only insofar as they guide the physician to a correct diagnosis. ${ }^{12}$ This philosophy dictates that once the diagnosis is made (e.g., cancer) and the disease is treated (e.g., chemotherapy), the symptoms (e.g., breathlessness, pain) will dissipate.

What is left unsaid is what happens when the disease can't be cured, or is only partially treated or managed, or the treatment itself results in temporary or permanent distress and disability. ${ }^{12}$ As a result, current clinical practice regarding symptoms is driven not by evidence but by extrapolation from other situations, small and underpowered or single site studies, and is often anecdotal or based on hearsay and therefore not based on valid science. ${ }^{12}$

\section{National Strategies and Frameworks for Palliative Care}

Identifying national strategies for palliative care is relatively problematic as most published reports are to be found in the "gray" literature or are contained within federal legislation. To identify reports that could inform this article, a rapid review was undertaken to identify relevant documents 
(see Sims \& Fassbender from this same issue). This review was then supplemented by the lead author's personal files, outreach to colleagues within the international palliative care community, review of European Association for Palliative Care publications, and a subsequent search of the table of contents of the major palliative care journals.

Frameworks were found for 10 countries. They ranged from detailed and comprehensive multi-year strategies addressing the four major barriers outlined above (Ireland, New Zealand, Australia, and United Kingdom) to more general strategies. The more general strategies typically include laws guaranteeing access to palliative care services for "dying" patients and their families or recommendations for the development of clinical infrastructure. Table 1 presents a summary of identified frameworks and their key components.

Few formal evaluations have been performed for the majority of national strategies. As well, minimal comparative data exist regarding the quality of care, access to palliative care services, timing of access in the disease trajectory, and patient and family satisfaction with care.

Cross-national comparisons of high income nations like Canada have been limited to studies reporting composite indices that describe the quality of death, ${ }^{13}$ measures of service provision, ${ }^{14}$ or examine sites of death. ${ }^{15}$ Despite these limitations, four countries typically emerge at the top of all palliative care rankings-Australia, Ireland, New Zealand, and the United Kingdom (Table 2). Perhaps not surprisingly, these countries have developed the most comprehensive national strategies and began addressing the issue of universal access to palliative care over a decade ago.

A brief review of each country's efforts in palliative care is summarized below and full details of the strategies may be found in Table 1.

\section{Australia}

Palliative care services have been part of national health policy for over two decades in Australia. ${ }^{16}$ The Australian Association of Hospice and Palliative Care published the first national standards for palliative care in $1994 .^{9}$ The most recent version published in 2005 (Table 1) contains 13 standards that have been incorporated and guided government policy. ${ }^{9}$

A NPCS was endorsed in October 2000 by the Australian Health Ministers' Advisory Council. ${ }^{17}$ The NPCS committed state and national governments, palliative care service providers, and community-based organizations to developing and implementing palliative care policies, strategies, and services that are consistent across Australia.

The NPCS set objectives and strategies to inform policy and service development in Australia, guide States and Territories in developing palliative care services, and support patient care agencies. ${ }^{17}$ It also provided the framework for collaboration between state and national governments to ensure that services were funded and that policy, planning, and service delivery were directed toward common and agreed goals. ${ }^{17}$

The NPCS resulted in programs that focused on enhancing access, improving care services, and increasing the evidence base. These included the following:

1. Building research capacity in the sector;

2. Palliative care curriculum development and implementation for all undergraduate health professionals' courses;
3. A national service improvement program through data collection, feedback, and service development;

4. A resource for more systematic access to the evidence base for practice and policy;

5. A rigorously evaluated tool to support needs-based palliative care so that specialist services are seeing the people with the most complex needs;

6. A national clinical trials program to improve systematically the evidence base for clinical practice; and

7. A major health systems research project to explore models of care. ${ }^{17}$

In 2010, the NPCS was reviewed and revised, a process that involved eight workshops, an online survey, and consultation with 127 stakeholder groups. ${ }^{10}$ The updated strategy focused on four goal areas: awareness and understanding, appropriateness and effectiveness, leadership and governance, capacity and capability. It also further integrated palliative care services into the national health system.

Most recently in 2015, the government funded 13 initiatives to enhance palliative care under the National Palliative Care Program. ${ }^{18}$ These initiatives focused on:

- Service provider skill development (frontline worker education and training);

- Service quality improvement (in acute and community health settings);

- Research and benchmarking (building and enhancing capacity within the palliative care sector);

- Advance care planning (strengthening understanding and uptake);

- Knowledge building and awareness (improving sector knowledge and community awareness);

- Improving collaboration and linkages between all Governments' palliative care activities; and

- Collating and distributing palliative care information across the sector.

Evaluation of these initiatives is pending.

\section{Ireland}

Ireland has one of the longest histories of voluntary and charitable hospice programs dating back to 1879 when the Irish Sisters of Charity opened Our Lady's hospice in Dublin. Government involvement in modern palliative care, however, did not begin until over 100 years later when the National Cancer Strategy (NCS) acknowledged the role palliative care played in improving the quality of life for cancer patients. ${ }^{18}$ The NCS established education curricula for nurses, physicians, and other allied health professionals focused on cancer. A subsequent government initiative, the Cancer Services Forum, defined how palliative care services should be organized and structured within the country.

Government attention to palliative care expanded beyond cancer in 1999 when the National Advisory Committee on Palliative Care (NACPC) was established by the Minister for Health and Children. ${ }^{19}$ The NACPC was charged with preparing and presenting a comprehensive report on existing service provision and the future requirements of palliative care services in Ireland.

Its report ${ }^{20}$ presented a detailed plan for specialist palliative care service provision in specialist units, acute general 


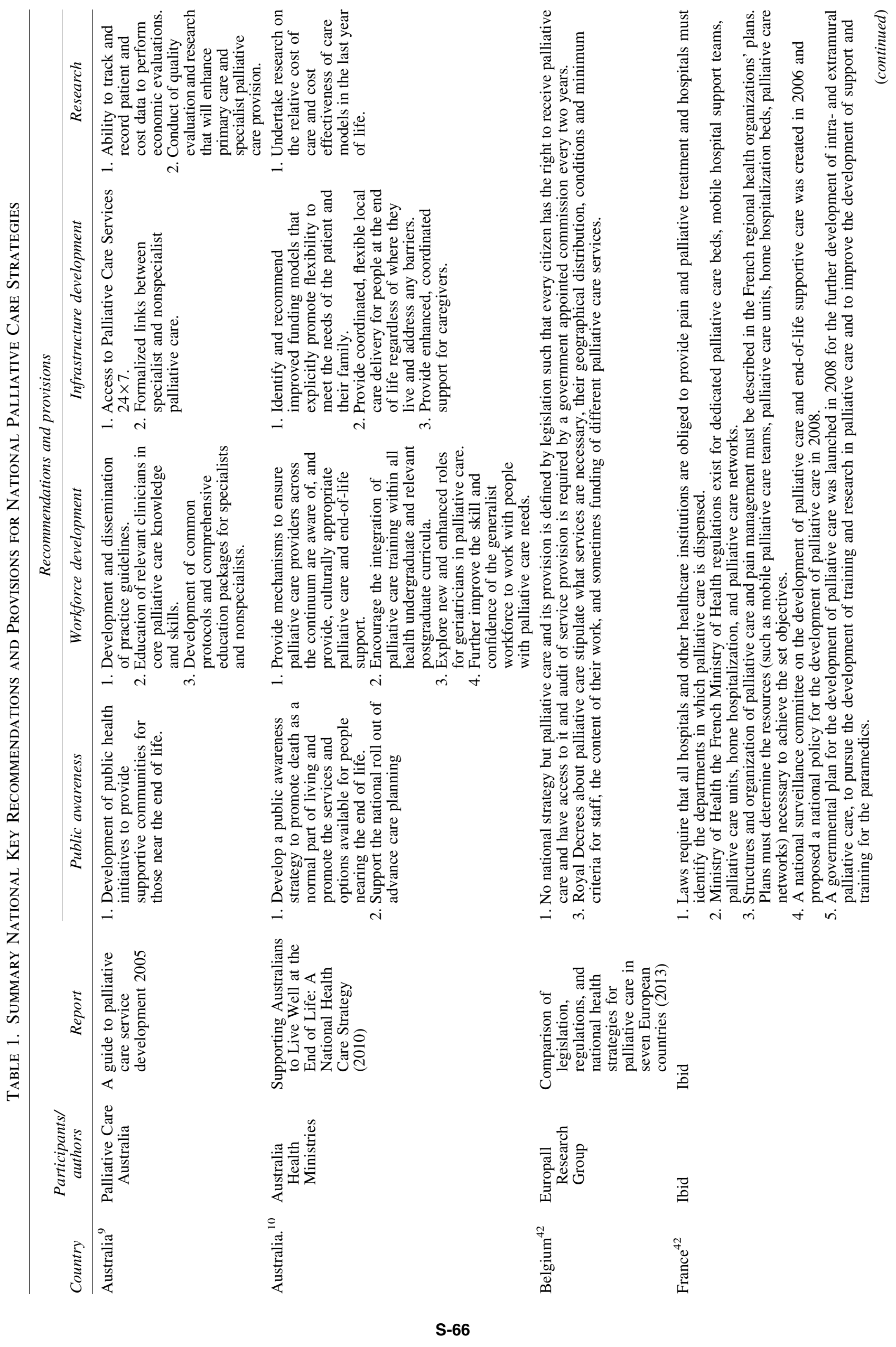




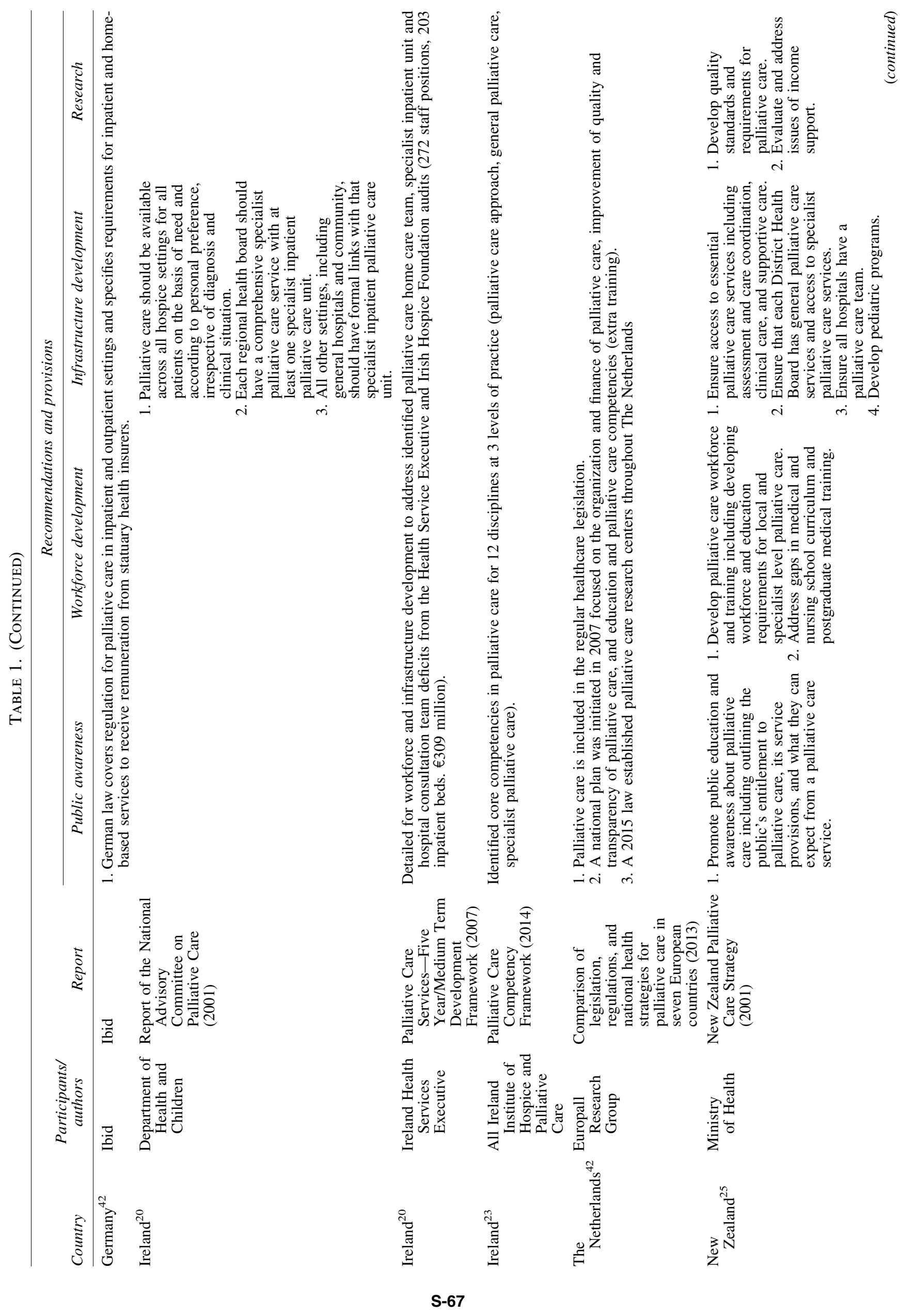




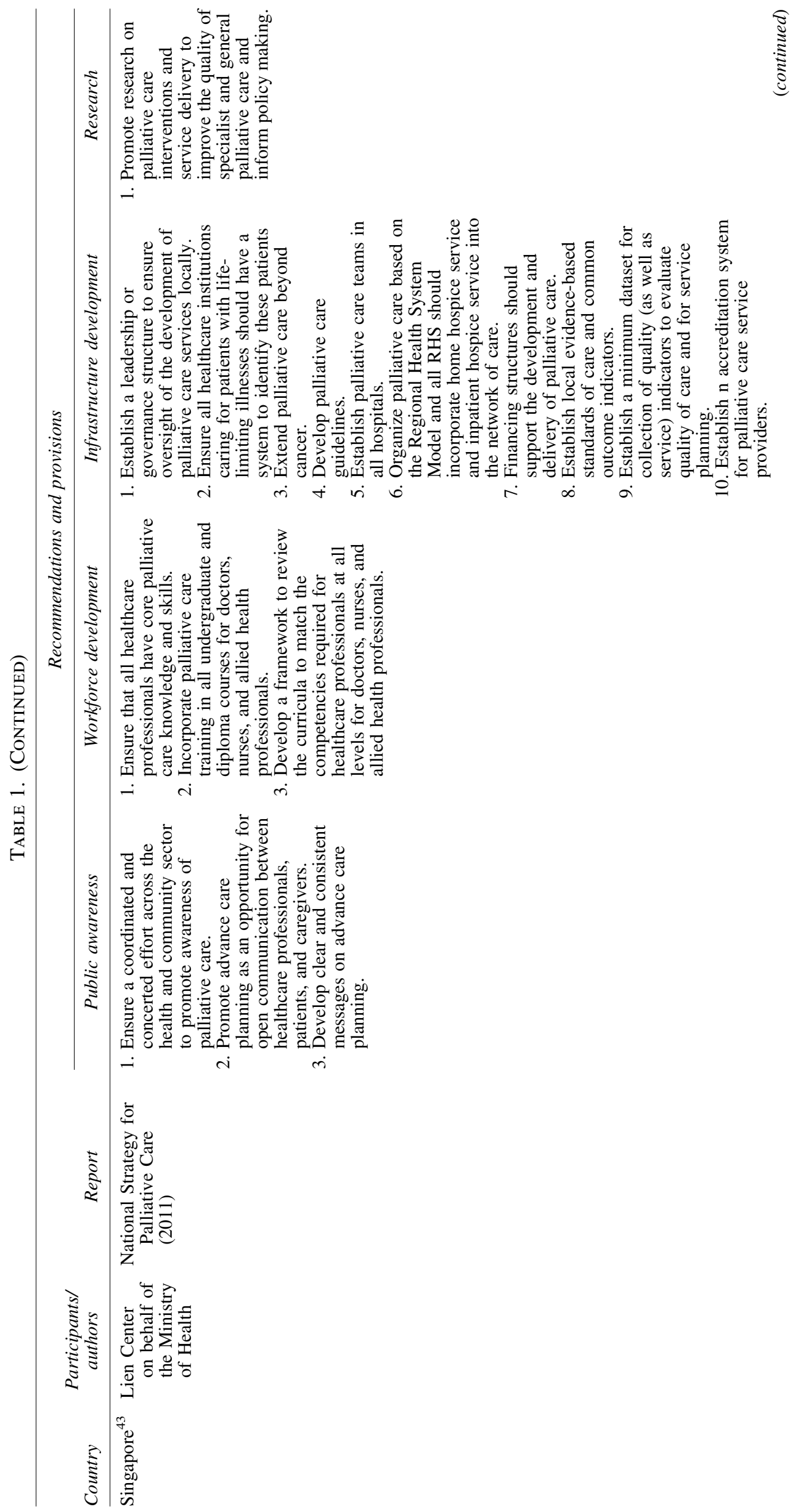




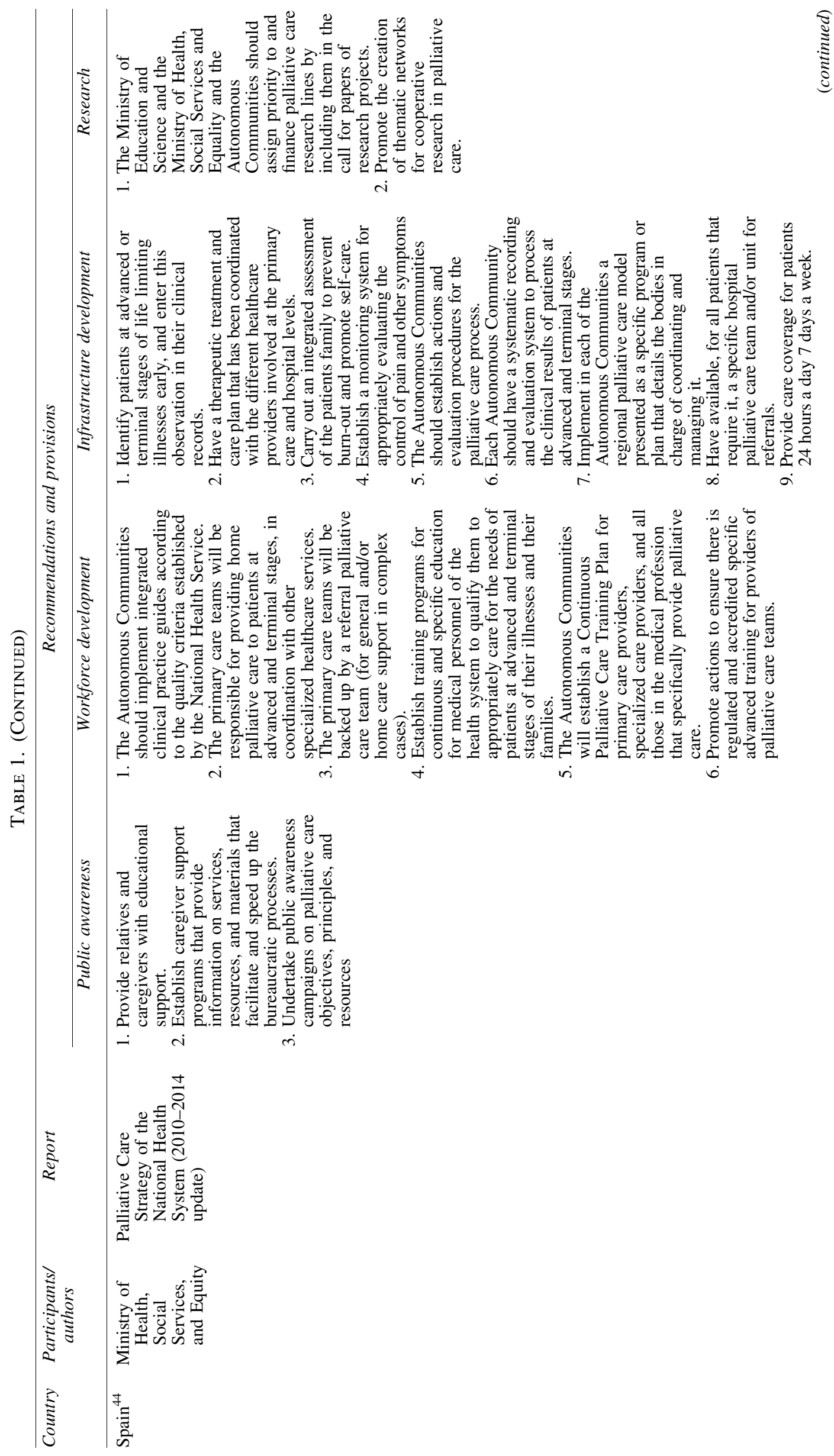




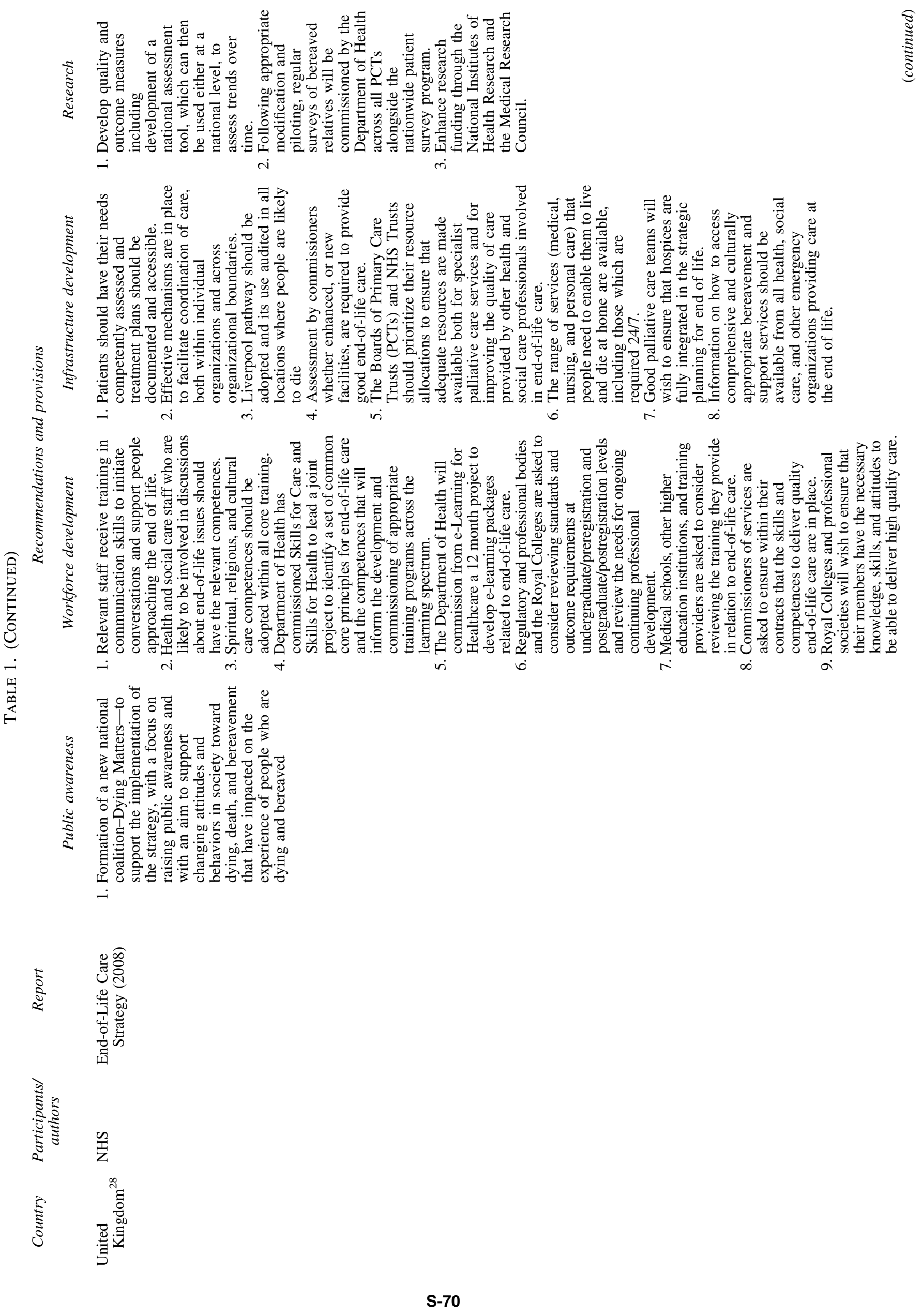




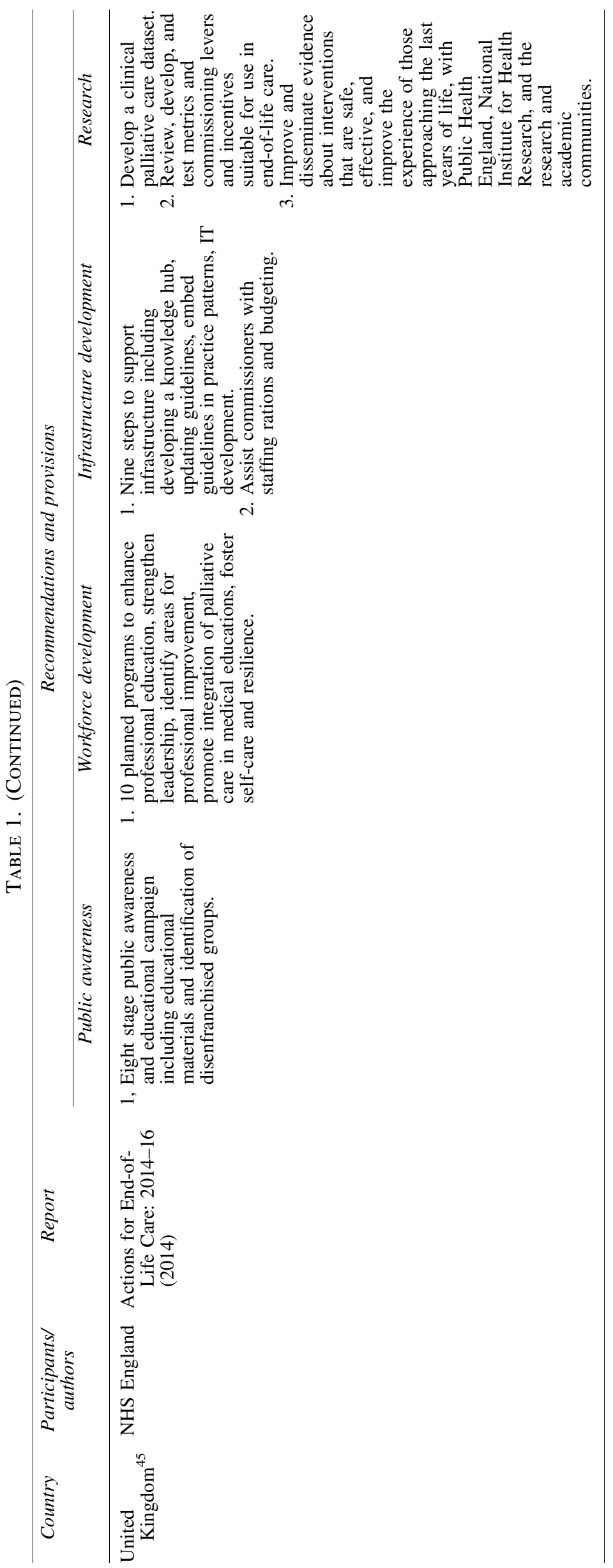


Table 2. International Rankings of Palliative Care

\begin{tabular}{|c|c|c|}
\hline Report & Basis of assessment & Findings and rankings \\
\hline $\begin{array}{l}\text { Economist Intelligence } \\
\text { Unit Quality of Death } \\
\text { Ranking (2015) }\end{array}$ & $\begin{array}{l}\text { Ranking of quality of palliative care available to adults } \\
\text { in } 80 \text { countries. Composite Index that includes } \\
\text { palliative and healthcare environment, human } \\
\text { resources, affordability of care, quality of care, } \\
\text { community engagement. Rankings are relatively } \\
\text { controversial given concerns of methodology }\end{array}$ & $\begin{array}{l}\text { Rankings: } \\
\text { 1. United Kingdom } \\
\text { 2. Australia } \\
\text { 3. New Zealand } \\
\text { 4. Ireland } \\
\text { 5. Belgium }\end{array}$ \\
\hline $\begin{array}{l}\text { EAPC Atlas of Palliative } \\
\text { Care in Europe }(2013)\end{array}$ & $\begin{array}{l}\text { Report of palliative care service provision in Europe. } \\
\text { Services included volunteer hospice teams, hospital } \\
\text { palliative care support teams, home palliative care } \\
\text { support teams, mixed palliative care support teams, } \\
\text { palliative care units in tertiary care hospitals, palliative } \\
\text { care teams in nontertiary hospitals, inpatient hospice, } \\
\text { day hospice/day care centers. }\end{array}$ & $\begin{array}{l}\text { Countries with }>16 \text { palliative } \\
\text { care services per person: } \\
\text { Belgium, Ireland, } \\
\text { Luxembourg, Sweden } \\
\text { Countries with } 12-16 \text { services } \\
\text { per person: The Netherlands, } \\
\text { Poland, United Kingdom }\end{array}$ \\
\hline $\begin{array}{l}\text { World Health Organization } \\
\text { and Worldwide Palliative } \\
\text { Care Alliance Global Atlas } \\
\text { of Palliative Care (2014) }\end{array}$ & $\begin{array}{l}\text { Countries where hospice-palliative care services are } \\
\text { at a stage of advanced integration into mainstream } \\
\text { service provision as characterized by the development } \\
\text { of a critical mass of palliative care activism in a wide } \\
\text { range of locations; comprehensive provision of all } \\
\text { types of palliative care by multiple service providers; } \\
\text { broad awareness of palliative care on the part of health } \\
\text { professionals, local communities and society in } \\
\text { general; unrestricted availability of morphine and all } \\
\text { other strong pain-relieving medicines; substantial } \\
\text { impact of palliative care upon policy, in particular } \\
\text { upon public health policy; the development of } \\
\text { recognized education centers; academic links forged } \\
\text { with universities; and the existence of a national } \\
\text { palliative care association }\end{array}$ & $\begin{array}{l}\text { Australia, Austria, Belgium, } \\
\text { Canada, France, Germany, } \\
\text { Hong Kong, Iceland, Ireland, } \\
\text { Italy, Japan, Norway, Poland, } \\
\text { Romania, Singapore, Sweden, } \\
\text { Switzerland, Uganda, United } \\
\text { Kingdom, United States of } \\
\text { America. }\end{array}$ \\
\hline
\end{tabular}

hospitals, and community. It also set standards, funding, accountability, planning and development, and service priorities. It further said that palliative care services should be structured into three levels of ascending specialization (palliative care approach, general palliative care, specialist palliative care); available in all care settings; and that services should allow patients to move from one care setting to another (Table 1).

The report issued four key recommendations:

1. An adequate level of public funding should be provided for the provision of palliative care services;

2. Priorities for the development of specialist palliative care services should be based on national policy and should be decided by Health Boards at regional level;

3. There should be a separate protected budget for specialist palliative care services at Health Board level; and

4. Health Boards should work in partnership with the voluntary service providers in their areas.

Implementation of the strategy was challenging. Between 2001 and 2004 statutory funding increased by only $€ 44$ million, €90 million short of the NACPC-specified budget. ${ }^{21}$ As well, in 2004 the ratio of investment between highest and lowest regions was 20:1. ${ }^{21}$

An Irish Hospice Foundation audit found that while more Medical Consultants in Specialist Palliative Medicine had been appointed, home care services extended, and the National Council for Specialist Palliative Care established, most facilities had not implemented the new framework, including a deficit of 254 specialist in-patient beds. ${ }^{22}$ Lack of progress was predictable as regions performed needs assessments and developed strategies. ${ }^{21}$ More than halfway into the five year strategy, universal access to primary, intermediate, and specialty palliative care services was well behind target.

In response to the audit, each Administrative Area of the Health Service Executive was tasked with auditing palliative care service provision against the recommendations of the NACPC Report. ${ }^{23}$ Deficits were identified, a set of priority actions detailed, and capital and revenue costs were estimated. ${ }^{23}$ From 2004 to 2007, annual government spending on palliative care services increased $40 \%$ from $€ 54$ million to D $€ 76$ million and palliative care availability expanded in all regions of the country. ${ }^{21}$

Unfortunately, the collapse of the Irish economy in 2008 essentially eliminated the Executive Health Service's ability to complete the NACPC recommendations in a timely fashion. It is only within the past several years, that Ireland has again focused on its intentions to enhance its palliative care infrastructure.

Whereas the timeline of government strategies for palliative care in Ireland mirrored that of Australia, the Irish results have fallen short of those of the Southern continent. The most obvious reason for the mixed results was both a shortfall of committed resources early in the course of the strategy and the subsequent Irish economic crisis. Nevertheless, policy oversights also contributed. The NACPC report focused strongly on the development of specialist palliative careparticularly in hospitals-whereas most patients required basic and intermediate palliative care.

It was only in 2014 that a national competence framework was launched by Department of Health and Department of 
Justice, Equality, and Defense to ensure that all healthcare professionals have training in the core knowledge and skills of palliative care. ${ }^{24}$ Second, the NACPC, although acknowledging geographic disparities, did little to address them. Regions with different baseline levels of palliative care services received equivalent levels of investment. ${ }^{25}$ Finally, unlike the Australian strategy, the Irish plan focused almost exclusively on infrastructure development. While workforce gaps were acknowledged, a concrete strategy to address them was not included in plan.

\section{New Zealand}

Published in 2001, the New Zealand Palliative Care Strategy was the culmination of a two year intensive project that included literature searches, needs analyses, surveys of palliative care providers, informal discussions with a variety of stakeholders including a Maori working party, public comment on draft documents, and 12 public meetings and focus groups around New Zealand. ${ }^{26}$

Like Australia, the New Zealand strategy addressed all four barrier groups-public awareness, workforce gaps, infrastructure, and research. The strategy was part of an overall National Health Care Strategy of the prior year (2000). The resulting National Strategy outlined nine components (Table 1) with a funding commitment by the government to enact them over 5-10 years.

As in Ireland, immediate results of the strategy were mixed. A review of progress by the Palliative Care Council of New Zealand-an organization established by Cancer Control New Zealand to provide independent and expert advice to the Minister of Health, and to report on New Zealand's performance in providing palliative and end-of-life carehighlighted progress in areas of workforce development and quality requirements but noted a number of ongoing challenges. ${ }^{27}$ These challenges related to the following:

- Inequality of access; particularly based on diagnosis, but also in relation to ethnicity, age, and geographic location;

- Lack/absence of data on population need, service provision, and service utilization;

- Lack of awareness/utilization of palliative care services among the general public and healthcare professionals;

- Lack of inclusion in national health policy and strategic planning; and a

- Lack of a national strategic approach to research in palliative care. ${ }^{27}$

The council issued a series of recommendations to address each of these issues (Table 1).

Subsequent reports examined the key drivers of palliative care need in New Zealand $(2011)^{28}$ and access to palliative care $(2013)^{29}$ Overall, service delivery and the basic infrastructure supporting specialist palliative care services was seen as adequate, particularly in hospitals and hospices. Gaps included access to community based specialist level palliative medicine physicians, geographic and ethnic disparities in access, limited inclusion of palliative care in undergraduate medical and nursing school curricula, and gaps in after-hour coverage. The report made 25 recommendations to the Ministry of Health, District Health Boards, Education Providers, and Researchers. ${ }^{29}$
Subsequently the New Zealand Government allocated $\$ 76.1$ million (NZ) in 2015 to palliative care services, created 60 new palliative care positions, and ordered another audit and review by the Ministry of Health due in 2016. The Ministry report is to include the following:

- Current service capability and capacity across all care settings and providers;

- Projected need for palliative care services from 2016 to 2036;

- Gaps and barriers to achieving high quality and equitable provision of care including workforce issues, funding settings, and standards of care;

- Actions to improve integrated services across all providers and care settings from 2016 to 2021;

- Actions to improve access to, and quality and standards of care, and ensure equitable provision of care over the next three to five year within existing funding levels. ${ }^{30,31}$

In sum, New Zealand has recommitted to the development of palliative care services in the country following its 2010 audit. Regular ongoing national audits to track progress (2010, 2011, 2013, and a planned report in the fall of 2016) and major government investments in service delivery have appeared to improve access to palliative care considerably across the nation.

\section{United Kingdom}

Perhaps not surprisingly given that the first modern day hospice was established in London (St. Christopher's), the United Kingdom consistently ranks as one of the top countries in world for the provision of palliative care. ${ }^{13,14}$ Perhaps due to the strength of its voluntary and charitable hospice infrastructure, an official government strategy for United Kingdom palliative care was developed in $2008,{ }^{32}$ a decade or more after the strategies of Australia, Ireland, and New Zealand were published.

The Department of Health's End of Life Care Strategy: Promoting High Quality Care for all Adults at the End of Life $^{32}$ was an extremely comprehensive report that addressed all four major barriers to universal palliative care (awareness, education, workforce, and infrastructure (Table 1). A companion report, Better Care, Better Lives, ${ }^{33}$ published the same year focused on ensuring access to palliative care for children with a life-limiting or life-threatening condition. The U.K. Government committed £286 million (over 20092011) to support the implementation of the End of Life Care strategy. ${ }^{32}$

Although the comprehensive strategy was not published until 2008, the report did build on a number of early government efforts dating back to 2000. In that year, The NHS Cancer Plan: A Plan for Investment, a Plan for Reform identified palliative care as an integral component of cancer care. ${ }^{34}$ Four years later, the National Institute for Health and Clinical Excellence developed a guidance for cancer palliative care. ${ }^{35}$ Palliative care was also recognized for a number of noncancer conditions including chronic kidney disease (2005), ${ }^{36}$ dementia (2006), ${ }^{37}$ Parkinson's disease (2006), ${ }_{39}^{38}$ and in the recommended Standards for NHS HIV Services. ${ }^{39}$

Evaluation of the U.K. strategy has only just begun and data on its implementation are sparse. A recently published article by Gao et al. found that in-hospital death rates began to 
decline in England and hospice and home deaths rose after the strategy was enacted. ${ }^{11}$ Other elements of the strategy including public awareness, workforce development, and infrastructure changes - with the notable exception of the widely publicized issues with the Liverpool Pathway rollout $^{40}$ — await ongoing audit.

\section{Implications}

Research has conclusively demonstrated that many seriously ill Canadians experience treatable suffering. Palliative care offers a rational solution to this problem by improving quality of life and care. How palliative care can be rapidly inserted into the genome of Canadian medicine is a critical policy and societal question that needs a rapid answer.

Examples of national strategies from countries similar to Canada are few and the key factors associated with their success (or failure) have yet to be conclusively determined. An examination of the experience of the four countries and additional insights from other strategies detailed in Table 1 do, however, suggest a number of common themes.

- Input and early involvement of senior policy makers into strategy development is clearly important. Countries where such involvement has not occurred (i.e., guidelines have been created by professional societies in isolation) appear to be less successful. Comprehensive strategies that address all four major barriers to universal access and that involve the key constituents within each (clinicians, educators, researchers, service providers, advocates, policy makers) appear to have been more successful.

- A clear focus on enhancing the evidence base and developing a national system of quality reporting as evidenced by the Australian experience also appears to be key indicator of likely success. Regular planned audit of the strategy's outcomes and milestones appears to have moved New Zealand's efforts forward after a relatively slow start.

- Finally, and perhaps most importantly, a commitment to the WHO's resolution of universal access to high palliative care requires substantial and sustained investment by government funding bodies as evidenced by Australia, New Zealand, and the United Kingdom. This investment needs to be accompanied by public awareness campaigns that are driven by market research and not focused on the task of changing the culture of death and dying in Canada.

Significant investments need to be made in undergraduate and graduate medical, nursing, and social work training to develop both specialist palliative care professionals and nonspecialists who nevertheless have core palliative care knowledge and skills. Similar effort need to be focused on continuing education for the generation of healthcare professionals already in practice who never learned these skills in their training.

Finally, the Canadian Institutes of Health Research need to dramatically increase their current level of funding for palliative care beyond the existing level of $0.03 \%$ of available research dollars. By better matching treatments to patients' goals, reducing unnecessary and unwanted hospitalizations and emergency department visits, and enhancing caregiver support, needed investments will be recouped rather quickly. Even if they are not, we owe our rapidly aging population the promise of a better future.

As the American politician and former Vice-President Hubert Humphrey said in his last speech, "the moral test of government is how that government treats those who are in the dawn of life, the children; those who are in the twilight of life, the elderly; and those who are in the shadows of life; the sick, the needy and the handicapped.",41

\section{Acknowledgments}

The author acknowledged the contributions of the Palliative Care Matters Research Support Team: Sharna Polard and Roger Salus for library services and literature searching; Heather Styles and Michelle Sims for overall research coordination and assistance; and Michelle Sims for literature screening, literature review, and project support.

\section{Author Disclosure Statement}

RSM is supported by the National Palliative Care Research Center, an American Cancer Society Clinical Research Professorship, and by the Claude D. Pepper Older Americans Independence Center at the Icahn School of Medicine at Mount Sinai (Grant No. 5P30AG028741). The views expressed in this article are those of the authors and do not necessarily reflect the position or policy of the Department of Veterans Affairs or the United States government.

\section{References}

1. World Health Organization: Strengthening of Palliative Care as a Component of Comprehensive Care Throughout the Life Course. Sixty-seventh World Health Assembly; 2014; Geneva: World Health Organization, 2014.

2. Rocker G, Downar J, Morrison RS: Palliative care for chronic illness: Driving change. CMAJ 2016;188:E493-E498.

3. Canadian Hospice Palliative Care Association: The Way Forward National Framework: A Roadmap for an Integrated Palliative Approach to Care. Ottawa: The Way Forward Initiative, 2015.

4. An Act providing for the development of a framework on palliative care in Canada, Bill C277, First session, 42nd Congress, 2017.

5. Alberta Health Services: Palliative and End of Life Care: Alberta Provincial Framework [Internet]. Edmonton: Alberta Health Services, 2014. www.albertahealthservices.ca/assets/ info/seniors/if-sen-provincial-palliative-end-of-life-careframework.pdf (last accessed November 12, 2016).

6. Schenker Y, Crowley-Matoka M, Dohan D, et al.: Oncologist factors that influence referrals to subspecialty palliative care clinics. J Oncol Pract 2014;10:e37-e44.

7. Hanratty B, Hibbert D, Mair F, et al.: Doctors' understanding of palliative care. Palliat Med 2006;20:493-497.

8. Canadian Medical Association: Palliative Care: Canadian Medical Association's National Call to Action. Ottawa, 2015.

9. Palliative Care Australia: Standards for Providing Quality Palliative Care for all Australians. Deakin West, Australia, 2005.

10. Australian Health Ministeries: Supporting Australians to Live Well at the End of Life: National Palliative Care Strategy. Canberra, 2010. 
11. Gao W, Ho YK, Verne J, et al.: Project GUC. Changing patterns in place of cancer death in England: A populationbased study. PLoS Med 2013;10:e1001410.

12. von Gunten $\mathrm{CF}$ : Interventions to manage symptoms at the end of life. J Palliat Med 2005;8(Suppl 1):S88-S94.

13. The Economist Intelligent Unit: The 2015 Quality of Death Index: Ranking Palliative Care Across the World. London, 2015.

14. Centeno C, Lynch T, Donea O, et al.: EAPC Atlas of Palliative Care in Europe 2013. Milan: European Association for Palliative Care, 2013.

15. Bekelman JE, Halpern SD, Blankart CR, et al.: Comparison of site of death, health care utilization, and hospital expenditures for patients dying with cancer in 7 developed countries. JAMA 2016;315:272-283.

16. Currow DC: The PRISMA symposium 3: Lessons from beyond Europe. Why invest in research and service development in palliative care? An Australian perspective. J Pain Symptom Manage 2011;42:505-510.

17. Department of Health and Ageing: Naional Palliative Care Strategy. Canberra, 2000.

18. National Palliative Care Projects [Internet]. Department of Health. http://health.gov.au/internet/main/publishing.nsf/ content/palliativecare-program.htm (last accessed September 1, 2016).

19. Connolly M, Charnley K, Regan J: A Review of Palliative Care Competence Frameworks. The Palliative Care Competency Framework Development Project Steering Group, Dublin, 2012.

20. Department of Health and Children: Report of the National Advisory Council on Palliative Care. Dublin: Ireland Department of Health, 2001.

21. May P, Hynes G, McCallion P, et al.: Policy analysis: Palliative care in Ireland. Health Policy 2014;115:68-74.

22. Irish Hospice Foundation: The Baseline Study on the Provisions of Hospice/Specialist Palliative Care Services in Ireland. Dublin, 2006.

23. Health Services Executive: HSE National Service Plan. Dublin, 2007.

24. Connolly M, Ryan K, Charnley K: Developing a palliative care competence framework for health and social care professionals: The experience in the Republic of Ireland. BMJ Support Palliat Care 2016;6:237-242.

25. May P, Hynes G, McCallion P, et al.: Challenges in increasing regional equity in palliative care service provision in Ireland. Eur J Palliat Care 2013;20:130-133.

26. Ministry of Health: The New Zealand Palliative Care Strategy. Wellington, 2001.

27. Naylor W: Positioning Palliative Care in New Zealand: A Review of Government Health Policy in Relation to the Provision of Palliative Care Services in New Zealand. Palliative Care Council of New Zealand, Wellington, NZ, 2010.

28. Naylor W: National Health Needs Assessment for Palliative Care: Phase 1 Report: Assessment of Palliative Care Need. Palliative Care Council of New Zealand, Wellington, NZ, 2011.

29. Naylor W: National Health Needs Assessment for Palliative Care Phase 2 Report: Palliative Care Capacity and Capability in New Zealand. Palliative Care Council of New Zealand, Wellington, NZ, 2013.
30. Ministry of Health: "Review of adult palliative care services in New Zealand." Wellington, 2015.

31. Department of Treasury, Government of New Zealand: "2015 budget speech." Wellington, 2015.

32. United Kingdom Department of Health: "End of Life Care Strategy: Promoting High Quality Care for All Adults at the End of Life." London, 2008.

33. United Kingdom Department of Health: Better Care: Better Lives. London, 2008.

34. United Kingdom Department of Health: NHS Cancer Plan: A Plan for Investment, a Plan for Reform. London, 2008.

35. National Institute for Health and Clinical Excellence: Improving Supportive and Palliative Care for Adults with Cancer. London: National Institute for Health and Clinical Excellence, 2004.

36. United Kingdom Department of Health: National Service Framework for Renal Services-Part Two: Chronic Kidney Disease Acute Renal Failure and End of Life Care. London: Department of Health, 2005.

37. National Institute for Health and Clinical Excellence: Dementia: Supporting People with Dementia and their Carers in Health and Social Care. London: National Institute for Health and Clinical Excellence, 2004.

38. National Institute for Health and Clinical Excellence: Parkinson's Disease in Over 20s: Diagnosis and Management. London: National Institute for Health and Clinical Excellence, 2004.

39. Medical Foundation for AIDS \& Sexual Health: Recommended Standards for NHS HIV Services. London, 2003.

40. Independent Review of the Liverpool Pathway. More care, less pathway: A review of the Liverpool pathway. The Gold Standards Framework: Shrewsbury, United Kingdom. 2013.

41. Humphrey HH: Remarks at the dedication of the Hubert $\mathrm{H}$. Humphrey Building. Cong Rec 1977;123:37287.

42. Van Beek K, Woitha K, Ahmed N, et al.: Comparison of legislation, regulations and national health strategies for palliative care in seven European countries (Results from the Europall Research Group): A descriptive study. BMC Health Serv Res 2013;13:275.

43. Lien Center for Palliative Care: Report on the National Strategy for Palliative Care. Singapore: Duke-NUS Graduate Medical School, 2011.

44. Ministry of Health, Social Services, and Equality. Palliative care strategy of the National Health System, 2010-2014. Government of Spain: Madrid. 2012.

45. NHS England: Actions for End of Life Care: 2014-16. NHS, Redditch, United Kingdom, 2014.

Address correspondence to: R. Sean Morrison, MD

Brookdale Department of Geriatrics and Palliative Medicine

Icahn School of Medicine at Mount Sinai

Box 1070

New York, NY 10029

E-mail: sean.morrison@mssm.edu 